\title{
Preface to the MME Special Focus Issue on Managing Gangue Minerals
}

\section{Yongjun Peng ${ }^{1} \cdot$ Tarun Bhambhani ${ }^{2}$}

Published online: 22 March 2021

(C) Society for Mining, Metallurgy \& Exploration Inc. 2021

Over the years, mining has continued to play significant roles in global industrialization and technological advancements. Worldwide demand for valuable mineral products and metals like copper (Fig. 1) has been growing owing to accelerating progress on the technological front in the modern world, such as in communications, infrastructure and renewable energy technologies including electric vehicles, solar power and wind power. With the depletion of high-quality and economic ore reserves, however, concerns are rising over the limited global supplies of valuable and critical commodities such as rare earths, platinum group metals, nickel, cobalt and lithium.

The average feed grade for ores has been declining, as exemplified for copper in Fig. 2. Current and future ore bodies are increasingly complex, containing more problematic gangue mineral species and larger amounts of them. This makes management of the gangue more complicated as well as more expensive, especially in terms of energy, chemicals and water usage. This, consequently, is exerting pressure on mineral processing and extractive metallurgy to produce highquality mineral and metal products efficiently and economically. As such, innovative practices to mitigate the detrimental effects of gangue on the environment and across the value chain in the mining industry are required. State-of-the-art knowledge to manage gangue minerals in pre-concentration, mineral separation and extractive metallurgy processes deserves further discussion.

In comminution circuits, gangue minerals are problematic as they contribute to increasing energy consumption. Considering different ore characteristics, it is still difficult to design process routes that can effectively process valuables

Yongjun Peng

yongjun.peng@uq.edu.au

1 School of Chemical Engineering, The University of Queensland, St Lucia, Brisbane, QLD 4072, Australia

2 Solvay Mining Solutions, Stamford, CT, USA and isolate gangue, particularly for variable feeds and coarse particles. Comminution equipment such as autogenous grinding $(\mathrm{AG}) /$ semi-autogenous grinding (SAG) and high-pressure grinding roll (HPGR) mills have been replacing traditional milling systems for size reduction to liberate the value minerals [3]. However, comminution processes are, in general, still inefficient and expensive, with approximately $50 \%$ energy consumption for most processing plants [4]. Microwave and high-voltage pulse treatment of ores along with preconcentration and early gangue rejection are considered as promising economical steps to increase the throughput of the entire processing circuit while decreasing the energy consumed per unit of metal produced. Some of the latest advances incorporated in pre-concentration routes during flowsheet development include bulk ore sorting through advanced online detecting sensors (using X-rays, optical sorting and scanning electron microscopy), coarse gangue rejection through fluidization classification, triboelectrostatic belt separation and magnetic and density separation [5]. A critical review to outline the existing and recent technological developments on ore sorting, coarse particle flotation and dry stack tailings which improve the viability of marginal deposits by rejecting coarse, liberated waste early in the metallurgical processing cycle is paramount. These breakthrough technologies in addition to comminution circuit modeling require attention in a quest to enhance gangue rejection.

For more than a century, flotation has been a widely adopted technique in mineral processing to separate valuable minerals from gangue. It is an intricate process, however, that is influenced by an array of variables including chemistry (such as reagents and pulp conditions), equipment (such as cell design, agitation and air flowrate) and operational factors (such as feed rate, particle size, pulp density and temperature). Nowadays, the flotation separation process is encountering major difficulties due to the influence of fine gangue minerals such as silicates and clay minerals, which cause high gangue entrainment, slime coatings and high pulp and froth viscosities. The presence of high amounts of iron sulfides and 


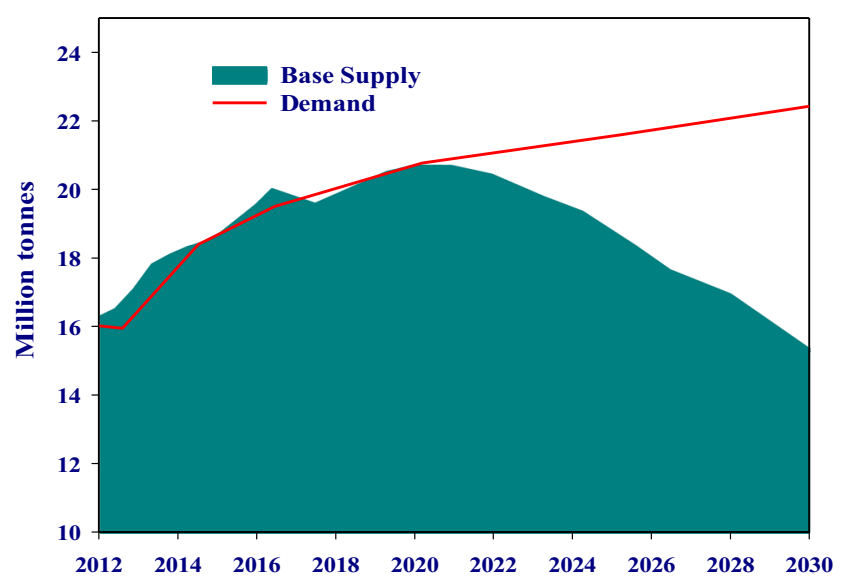

Fig. 1 Copper supply and demand [1]

naturally floatable gangue minerals such as organic carbon, graphite and talc is also problematic in flotation. These gangue minerals not only negatively impact the overall efficiency of the flotation process but also cause downstream issues like high emissions of direct and indirect greenhouse gases, such as carbon dioxide and sulfur dioxide, from smelting. Optimization of key flotation parameters and modeling to minimize flotation process inefficiencies remain arduous, particularly in the presence of multifarious gangue, low-grade and fine-grained ores. Despite a continuum of research advancements that have demonstrated how gangue minerals can be separated during flotation - for example, the development of bio-based polymers to deal with clay minerals [6], activated iron sulfides [7] and naturally floatable gangue minerals [8] — selectivity remains unsatisfactory, which hinders industrial application. Thus, further research relevant to advancing selective gangue rejection in flotation spanning, but not limited to, critical and precious minerals, sulfides and nonsulfides remains significant. With the hindsight of the growing advocacy for innovative green technologies, the direction should be further exploring remedial eco-friendly strategies for the management of gangue minerals, naturally hydrophobic or hydrophilic.

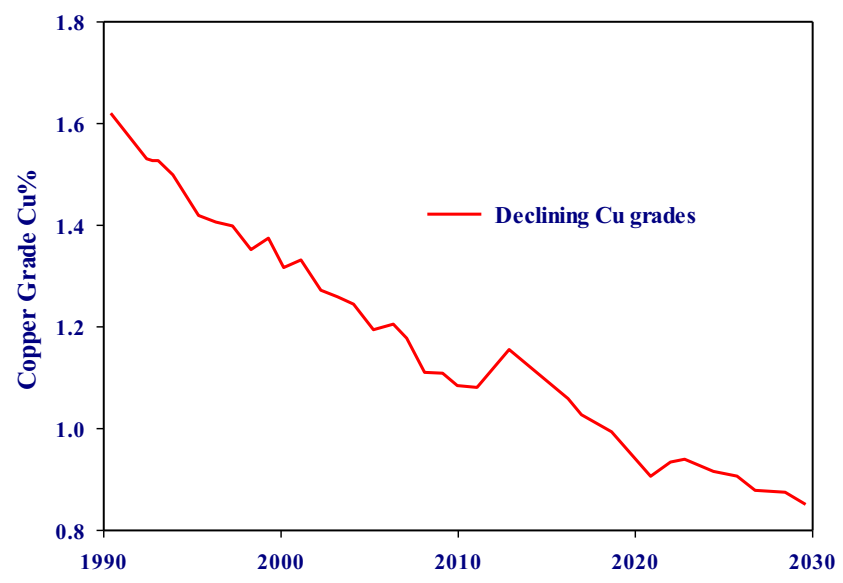

Fig. 2 Copper ore grade decline [2]
In the context of extractive metallurgy, gangue minerals react and complex with lixiviants and targeted elements, and this not only results in the large consumption of reagents but also compromises the recovery of valuable and critical elements. The process also produces salts and wastewater, which may be harmful to the environment and needs to be disposed of sustainably. Common hydrometallurgical processes include heap or dump leaching, bioleaching, in situ leaching, reactor leaching and autoclave leaching as well as solvent extraction and electrowinning. However, the micro- and macro-scale processes and the interactions during the hydrometallurgical processes are still imperfectly understood to aid further improvements of gangue removal [9]. For bioleaching, difficult and expensive bacterial treatments and long leaching periods to dissolve all the required valuables away from the gangue limit the effectiveness of the process. Alternative environmentally benign lixiviants such as ionic liquids or deep eutectic solvents have been considered. Concerted efforts are still required to tackle gangue minerals in extractive metallurgy efficiently. As a first step, detailing the most recent innovations, concerns and challenges encountered in the management of gangue minerals in different hydrometallurgical processes for a range of commodities is essential to achieve success.

As mining is a cornerstone to the rising global demand for essential commodities, this special issue on gangue management will be important to showcase novel advances on how gangue minerals can be innovatively managed during the processing of the prevailing low-grade ores. The special issue will also provide reliable frameworks for guiding mining policy formulations, contribute to the net-zero emissions agenda and climate change mitigation as well as ensuring global economy and environmental sustainability.

Special Focus Issue Editors Yongjun Peng and Tarun Bhambhani.

\section{References}

1. A candidate for "deal of the year" in British Columbia, (2018). http:// www.mining.com/web/candidate-deal-year-british-columbia/

2. Copper mining: articulating a contrarian thesis | MOI Global, (2017). https://moiglobal.com/copper-mining-articulating-a-contrarianthesis/

3. Wills BA, Napier-Munn T (2006) In: Mineral processing technology: an introduction to the practical aspects of ore treatment and mineral recovery. Books, Elsevier Science \& Technology

4. Pérez-García EM, Bouchard J, Poulin E (2018) Integration of a liberation model in a simulation framework for comminution circuits. Miner Eng 126:167-176

5. Galvin K, Iveson S (2014) Gravity separation and flotation of fine particles using the Reflux Classifier platform. In: 27th Int. Miner. Process. Congr., IMPC 2014.

6. Liu Q, Chena X, Lauten RA, Peng Y, Liu Q (2018) Mitigating the negative effects of clay minerals on gold flotation by a lignosulfonate-based biopolymer. Miner Eng 126:9-15 
7. Mu Y, Lauten RA, Peng Y (2016) The depression of copperactivated pyrite in flotation by biopolymers with different compositions. Miner Eng 96-97:113-122

8. Chimonyo W, Fletcher B, Peng Y (2020) The differential depression of an oxidized starch on the flotation of chalcopyrite and graphite. Miner Eng 146:106114
9. Norgate T, Jahanshahi S (2010) Low-grade ores - smelt, leach or concentrate? Miner Eng 23:65-73

Publisher's Note Springer Nature remains neutral with regard to jurisdictional claims in published maps and institutional affiliations. 